\title{
Deregulation of $\mathrm{miR}-183$ and KIAA0101 in aggressive and malignant pituitary tumors
}

\begin{abstract}
Magali Roche ${ }^{1,2,3}$, Anne Wierinckx ${ }^{1,2,4}$, Séverine Croze ${ }^{2,4}$, Catherine Rey ${ }^{4}$, Catherine Legras-Lachuer ${ }^{2,3,4,5}$, Anne-Pierre Morel ${ }^{1}$, Alfredo Fusco ${ }^{6,7}$, Gérald Raverot ${ }^{2,8,9}$, Jacqueline Trouillas ${ }^{2,8,10}$ and Joel Lachuer ${ }^{1,2,4 *}$

${ }^{1}$ Centre de Recherche en Cancérologie de Lyon, INSERM U1052/CNRS UMR 5286 Centre Léon Bérard, Lyon, France, ${ }^{2}$ Université Lyon 1, Université de Lyon, Lyon, France, ${ }^{3}$ ViroScan3D, Trévoux, France, ${ }^{4}$ ProfileXpert, SFR-Est, CNRS UMRS3453, INSERM US7, Lyon, France, ${ }^{5}$ UMR CNRS 5557 UCBL USC INRA 1193 ENVL, Dynamique Microbienne et Transmission Virale, Lyon, France, ${ }^{6}$ Instituto di Endocrinologia ed Oncologia Sperimentale del CNR c/o Dipartimento di Biologia e Patologia Cellulare e Molecolare, Facoltà di Medicina e Chirurgia di Napoli, Università degli Studi di Napoli "Federico II", Naples, Italy, ${ }^{7}$ Instituto Nacional de Câncer (INCA), Rio de Janeiro, Brazil, ${ }^{8}$ UMR 5292, Centre de Neurosciences de Lyon, CNRS, INSERM S1028, Lyon, France, ${ }^{9}$ Fédération d'Endocrinologie, Groupement Hospitalier Est, Hospices Civils de Lyon, Lyon, France, ${ }^{10}$ Centre de Pathologie Est, Groupement Hospitalier Est, Hospice Civils de Lyon, Bron, France
\end{abstract}

Changes in microRNAs (miRNAs) expression in many types of cancer suggest that they may be involved in crucial steps during tumor progression. Indeed, miRNAs deregulation has been described in pituitary tumorigenesis, but few studies have described their role in pituitary tumor progression toward aggressiveness and malignancy. To assess the role of miRNAs within the hierarchical cascade of events in prolactin (PRL) tumors during progression, we used an integrative genomic approach to associate clinical-pathological features, global miRNA expression, and transcriptomic profiles of the same human tumors. We describe the specific down-regulation of one principal miRNA, miR-183, in the 8 aggressive (A, grade $2 b$ ) compared to the 18 non-aggressive (NA, grades 1a, 2a) $\mathrm{PRL}$ tumors. We demonstrate that it acts as an anti-proliferative gene by directly targeting KIAA0101, which is involved in cell cycle activation and inhibition of p53-p21-mediated cell cycle arrest. Moreover, we show that miR-183 and KIAA0101 expression significantly correlate with the main markers of pituitary tumors aggressiveness, Ki-67 and p53. These results confirm the activation of proliferation in aggressive and malignant PRL tumors compared to non-aggressive ones. Importantly, these data also demonstrate the ability of such an integrative genomic strategy, applied in the same human tumors, to identify the molecular mechanisms responsible for tumoral progression even from a small cohort of patients.

Keywords: pituitary tumor, PRL tumor, miRNA, integrative genomics, aggressiveness, malignancy

\section{Introduction}

Endocrine pituitary tumors are some of the most frequent intracranial tumors, and are generally considered benign. Nevertheless, many of these tumors (30-45\%) are invasive (1) and some are clinically aggressive with recurrences and resistance to medical treatment $(2,3)$. In 2004, the World Health Organization (WHO) classification identified the "atypical adenoma" with "uncertain malignancy" (4). Only tumors with metastasis were considered malignant. Our group previously studied tumor 
progression in prolactin (PRL) tumors, which have been characterized clinically, histologically, molecularly, and genetically (57). Recently, a new classification of the five immunohistochemical (IHC) types of pituitary tumors (GH, PRL, ACTH, FSH-LH, and $\mathrm{TSH}$ ) has been proposed, which introduces a grading that takes the invasion and the proliferation into account (7). However, the molecular events responsible for tumor progression from an aggressive to malignant phenotype remain unknown.

Transcriptomic studies comparing all types of pituitary tumors to normal pituitary have highlighted different deregulated genes and pathways [reviewed in Ref. (8)]. However, as all tumor types were combined, the comparison of gene expression was able to decipher mechanisms involved in tumorigenesis, but not those specifically involved in progression. A recent study coupling transcriptomic and DNA copy number analyses performed on one subtype of pituitary tumor, PRL tumors, has revealed the deregulation of genes connected in a specific signaling pathway that controls cell proliferation, as well as an allelic loss on chromosome 11 specifically associated with aggressiveness and malignancy (5, $6,8,9)$. Nevertheless, the driving role of these alterations during progression toward aggressiveness is still unknown.

To decipher the driving event(s) leading to aggressive and malignant phenotypes of PRL tumors, we explored the global alterations of microRNAs (miRNAs) expression. miRNAs are a class of small non-coding RNAs, between 21 and $25 \mathrm{nt}$ in length, involved in post-transcriptional regulation of gene expression (10). They act by binding to $3^{\prime}$-untranslated regions ( $3^{\prime}$-UTR) of target mRNAs, causing inhibition of translation or mRNA degradation (10). Several studies have shown that miRNAs are deregulated in many types of cancer and act as tumor suppressors or oncogenes depending on the function of the targeted genes [for review, see Ref. $(11,12)]$. Moreover, miRNAs seem to be involved in the regulation of many steps of tumor progression (12, 13) that are defined as hallmarks of cancer (chronic proliferation, resistance to cell death, unlimited replicative potential, induction of angiogenesis, invasion, and metastasis) (14).

Many studies have explored the role of miRNAs in pituitary tumorigenesis by comparing tumoral to normal pituitary [Table S1 in Supplementary Material; (15-29)]. To our knowledge, however, only one study has explored the alteration of miRNAs malignancy (21).

In this study, we have performed a genome-wide analysis of miRNA expression in the same non-aggressive and aggressive PRL tumor samples as those used in earlier analyses $(5,9)$. Further, we propose a strategy of data filtering to find candidate miRNAs involved in tumor progression toward aggressiveness and malignancy.

\section{Materials and Methods}

\section{Patients and Tumors Characteristics}

The 26 patients, 13 males and 13 females presenting with hyperprolactinemia without acromegaly, underwent surgery for pituitary tumors. None were operated under dopamine agonist treatment at the time of operation. Twenty-five patients were part of the Hypopronos cohort, previously published in Ref. $(6,7,9)$. By histology, all the tumors were sparsely granulated and expressed
PRL in almost all cells. Taking into account the invasion of the cavernous or the sphenoid sinus by MRI and the three markers of the cell cycle (mitoses, Ki-67, and p53), the tumors were classified into five grades (1a: non-invasive; $1 \mathrm{~b}$ : non-invasive and proliferative; $2 \mathrm{a}$ : invasive; $2 \mathrm{~b}$ : invasive and proliferative; and 3 : malignant) (7) and split into two groups, non-aggressive (grades 1a; $2 \mathrm{a} ; n=18$ ) or aggressive (grade $2 \mathrm{~b} ; n=8$ ), according to the pathological classification and clinical behavior during follow-up. Three tumors (\#3, \#4, and \#5) were considered malignant and classified as grade 3 based on the occurrence of metastasis during follow-up. The main clinical and pathological data are shown in Table 1. For all tumors, fragments were immediately frozen in liquid nitrogen after verification by the pathologist, and kept at $-80^{\circ}$ until molecular analysis. The same tumors have been used for different molecular analyses (microarrays, PCR, and CGH) recently published by our group $(5-7,9,30)$.

The study was approved by the ethics committee of Lyon, and informed consent was obtained for each patient according to French law. This authorization was given in the context of a larger French clinical study named HYPOPRONOS (Programme Hospitalier de Recherche Clinique National 27-43).

\section{Isolation of Total RNA}

Total RNA from pituitary tumors and normal pituitary was extracted using the miRNeasy Mini kit with DNase treatment (Qiagen, Venlo, Netherlands) according to the manufacturer's protocol. Total RNA from cell lines was extracted using miRNeasy Micro kit with DNase treatment (Qiagen) according to the manufacturer's protocol. Total RNA yield was measured by OD260 and the purity confirmed by reaching an A260/A280 ratio of 1.9:2.1 on a Nanodrop ND-1000. The quality was evaluated on nanochips with an Agilent 2100 Bioanalyzer (Agilent Technologies, Palo Alto, CA, USA) according to the manufacturer's protocol.

\section{miRNA Microarray Processing and Analysis}

Global miRNA expression was assessed in 12 of 26 PRL tumors (8 non-aggressive and 4 aggressive) (Table 1, tumors in bold) using Human miRNA Microarray v3, $8 \times 15 \mathrm{k}$ from Agilent Technologies. Microarrays were processed as described in the miRNA Microarray System with miRNA Complete Labeling and Hyb Kit version 2.4 September 2011 (available at http://www.genomics. agilent.com). Microarrays were scanned on an Agilent Scanner Type C. Data were extracted using Agilent feature extraction software 10.7. Data files (.txt) from Feature Extraction and then were normalized using spikes in Genespring Software 7.0 (Agilent Technologies). Statistical analysis was performed using Genespring software 7.0 to isolate differentially expressed miRNAs in aggressive-invasive vs. non-aggressive tumors. A miRNA transcript was considered differentially expressed if the difference gave a $p$-value $\leq 0.05$ in the Welch ANOVA parametric test, and showed a minimal 1.5 fold variation. Data are available on the GEO database under the accession number GSE46294. Some of these tumors were previously analyzed for transcriptomic profiling in Ref. (9).

\section{TaqMan Low Density Array Analysis}

TaqMan Low Density Array (Applied Biosystems, Carlsbad, CA, USA) allowed testing of a large subset of miRNAs by RT-qPCR 
TABLE 1 | Clinical and pathological data in 26 patients operated for PRL tumors.

\begin{tabular}{|c|c|c|c|c|c|c|c|c|c|c|}
\hline $\begin{array}{l}\text { Tumor } \\
\text { number }\end{array}$ & Sex & Age & $\begin{array}{c}\text { Preoperative } \\
\text { PRL plasma level }\end{array}$ & $\begin{array}{l}\text { Tumor } \\
\text { size }\end{array}$ & Invasion & $\mathrm{Ki}-67 \%$ & $\mathbf{P} 53 \%$ & $\begin{array}{l}\text { Tumor } \\
\text { grades }^{\mathrm{a}}\end{array}$ & Groups $^{b}$ & Postoperative events \\
\hline $1^{\star}$ & M & 66 & 2610 & Macro & Yes & 8 & 3 & $2 b$ & $A$ & Recurrence, death \\
\hline $2^{\star}$ & $\mathrm{F}$ & 54 & 440 & Macro & Yes & 4 & 1.3 & $2 b$ & $A$ & Recurrence \\
\hline $3^{\star}$ & M & 68 & 4170 & Macro & Yes & 10 & 2.3 & $2 b^{\star \star}$ & $A$ & Recurrence, metastasis, death \\
\hline $4^{\star}$ & $M$ & 54 & 400 & Macro & Yes & 20 & 1 & $2 b^{\star \star}$ & $A$ & Recurrence, metastasis, death \\
\hline $5^{\star}$ & $\mathrm{F}$ & 31 & 3000 & Macro & Yes & 30 & 10 & $2 b^{\star \star}$ & $A$ & Recurrence, metastasis, death \\
\hline $6^{\star}$ & $\mathrm{F}$ & 43 & 150 & Macro & Yes & 2.7 & 0.5 & $2 b$ & A & Recurrence \\
\hline 25 & $\mathrm{M}$ & 60 & 690 & Giant & Yes & 3.6 & 2.6 & $2 b$ & $A$ & Recurrence \\
\hline 26 & $M$ & 53 & 320 & Macro & Yes & 5.5 & 2 & $2 b$ & A & Recurrence \\
\hline $7^{\star}$ & M & 40 & 1700 & Macro & Yes & 0 & 0 & $2 a$ & NA & Persistence \\
\hline $8^{\star}$ & M & 42 & 1540 & Micro & Yes & 1.8 & 0 & $2 a$ & NA & Persistence \\
\hline $9^{\star}$ & $\mathrm{M}$ & 42 & 700 & Macro & No & 0 & 0 & $1 \mathrm{a}$ & NA & Remission \\
\hline $10^{\star}$ & $\mathrm{F}$ & 44 & 100 & Micro & No & 0 & 0 & $1 a$ & NA & Remission \\
\hline $11^{\star}$ & $M$ & 39 & 4080 & Giant & No & 1.3 & 0 & $1 a$ & NA & Remission \\
\hline $12^{*}$ & $\mathrm{~F}$ & 30 & 97 & Micro & No & 0 & 0 & $1 a$ & NA & Remission \\
\hline 13 & $\mathrm{~F}$ & 21 & 900 & Macro & No & 0 & 0 & $1 a$ & NA & Remission \\
\hline 14 & $\mathrm{~F}$ & 28 & 80 & Micro & No & 0 & 0 & $1 a$ & NA & Remission \\
\hline 15 & $\mathrm{~F}$ & 36 & 120 & Macro & No & 0 & 0 & $1 a$ & NA & ND \\
\hline 16 & $\mathrm{~F}$ & 25 & 120 & Micro & No & 0 & 0 & $1 \mathrm{a}$ & NA & Remission \\
\hline 17 & $\mathrm{~F}$ & 55 & 860 & Macro & No & 0 & 0 & $1 a$ & NA & Remission \\
\hline 18 & $\mathrm{~F}$ & 26 & 300 & Micro & No & 0 & 0 & $1 a$ & NA & Remission \\
\hline 19 & $M$ & 26 & 180 & Macro & Yes & 0.5 & 1 & $2 a$ & NA & Recurrence \\
\hline 20 & $F$ & 38 & 105 & Micro & Yes & 0 & 0 & $2 a$ & NA & Recurrence \\
\hline 21 & $M$ & 27 & 1000 & Giant & Yes & 0 & 0 & $2 a$ & NA & Persistence \\
\hline 22 & $\mathrm{M}$ & 52 & 810 & Macro & Yes & 0 & 0 & $2 a$ & NA & Persistence \\
\hline 23 & $\mathrm{~F}$ & 73 & ND & Macro & Yes & 0 & 0 & $2 a$ & NA & ND \\
\hline 24 & $\mathrm{M}$ & 45 & 1000 & Giant & Yes & 0 & 0 & $2 a$ & NA & Persistence \\
\hline
\end{tabular}

*Tumors used for CGH and transcriptomic profiling in Wierinckx et al. (9); tumors in bold used for miRnome analysis.

**These tumors were grade $2 b$ at the first surgery, and became grade 3 because metastasis appeared during follow-up

${ }^{a}$ Classification of the tumors according to Trouillas et al. (7).

${ }^{b}$ Tumors split in two groups: aggressive (A) and non-aggressive (NA) according to Wierinckx et al. (9).

in a single assay. Briefly, $500 \mathrm{ng}$ of total RNA was used for cDNA synthesis with the TaqMan microRNA Reverse Transcription kit according to the manufacturer's protocol. Then, miRNA expression analysis was performed by Real-Time PCR using the TaqMan MicroRNA Array (Applied Biosystems) according to the manufacturer's protocol and run on a 7900HT Fast Real-Time PCR System (Applied Biosystems). Threshold cycle (Ct) values provided an index of miRNA level. The level of miRNA RNU6 was used as an internal standard. Values were obtained using RQ Manager Software for analysis (Applied Biosystems) and the detection limit was 32Ct. Comparison between samples was made using Genespring software 7.0 (Agilent Technology).

\section{miRNA RT-qPCR}

Single miRNA expression was assessed in cell lines and 26 PRL tumors (18 non-aggressive and 8 aggressive tumors) using TaqMan microRNA assays (Applied Biosystems). Assays with the following identification numbers were used in this study: miR-183 no. 002269; miR-let-7g no. 002282; and RNU6B no. 001093. Briefly, RT primers were multiplexed to obtain mixed RT primers at $62.5 \mathrm{nM}$ each. Then, $40 \mathrm{ng}$ of total RNA was reversetranscribed using the TaqMan microRNA reverse transcription kit (Applied Biosystems) with the following modifications: primers at a $12.5 \mathrm{nM}$ final concentration, dNTP at $2 \mathrm{nM}$ final concentration, $100 \mathrm{U}$ of MultiScribe Reverse Transcriptase per reaction, RT Buffer $1 \times$ final concentration, and $5 \mathrm{U}$ of RNase inhibitor per reaction. The RT program used was $30 \mathrm{~min}$ at $16^{\circ} \mathrm{C}, 30 \mathrm{~min}$ at $42^{\circ} \mathrm{C}$, and $5 \mathrm{~min}$ at $85^{\circ} \mathrm{C}$. mRNA levels were analyzed by qPCR using TaqMan small RNA assays at $1 \times$ final concentration and TaqMan Universal PCR Master Mix II No UNG at $0.5 \times$ final concentration, run on a 7900HT Fast Real-Time PCR System with the following cycle: standard mode, $10 \mathrm{~min}$ at $95^{\circ} \mathrm{C}$ then 40 cycles of denaturation at $95^{\circ} \mathrm{C}$ for $15 \mathrm{~s}$ and hybridization and elongation at $60^{\circ} \mathrm{C}$ for $60 \mathrm{~s}$. Relative miRNA expression was measured using hsa-let-7g (shown to be constant among tumors by microarray) and $R N U 6 B$ as a reference with RQ Manager Software (Applied Biosystems).

\section{Gene Expression Analysis}

Five hundred nanograms of total RNA were reverse-transcribed using the iScript cDNA synthesis kit (Bio-Rad, Hercules, CA, USA) following the manufacturer's protocol. The cDNA synthesized was measured by RT-qPCR using FAST SYBR Green Master Mix (Applied Biosystems) following the manufacturer's recommendations. The PCR program was as follows: $95^{\circ} \mathrm{C}$ for $20 \mathrm{~s}$ then 40 cycles of denaturation at $95^{\circ} \mathrm{C}$ for $1 \mathrm{~s}$ and hybridization and elongation at $60^{\circ} \mathrm{C}$ for $20 \mathrm{~s}$ on a $7900 \mathrm{HT}$ Fast Real-Time PCR System. Relative expression analysis was performed using RQ Manager Software (Applied Biosystems) with the RPL4 gene as a reference. Primers were designed using the NCBI Primer-Blast algorithm. All primers are listed in Table S2 in Supplementary Material. 


\section{Cell Culture and Transfection}

HeLa cells (high proliferating rate) were cultured in DMEM with $10 \% \mathrm{FBS}$ and $1 \%$ penicillin/streptomycin (PS). ZR-75-1 cells (mammary epithelial cancer cell line, low proliferating rate) were cultured in RPMI with 10\% FBS, $1 \%$ Pyruvate, and $1 \%$ PS. Transfection of pre-miR miRNA precursor (Ambion for Life Technologies) was performed using $100 \mathrm{nM}$ final concentration of pre-miRNA precursor with SiPORT NeoFX Transfection Agent (Ambion) following the manufacturer's instructions. Three premiRNA precursors were used: hsa-pre-miR-183 (PM10426), the positive control hsa-pre-miR-1 (AM17150), and the negative control pre-miR miRNA precursor negative control \#1 (AM17110). Transfections of plasmids were performed using FuGENE ${ }^{\circledR} 6$ Transfection Reagent (Promega) following the manufacturer's instructions.

\section{Plasmids and Constructs}

The human pre-mRNA expression construct lenti-miR-183 (MI0000273) and scramble control hairpin in pCDH-CMVMCS-EF1-copGFP (CD511B-1) were purchased from System Biosciences (SBI, Mountain View, CA, USA). A pcDNA3 plasmid containing ETS2-flag purchased from Addgene (31) was used to express ETS2, with an empty pcDNA3 as a control. Following the supplier's instructions, the pmirGLO Dual-Luciferase miRNA Target Expression Vector (Promega, Madison, WI, USA) was used to measure the activity of miR-183 matching the target sequence in KIAA0101; sequences were cloned into the $3^{\prime}$-UTR of luciferase (sense, $5^{\prime}$-AAACTAGCGGCCGCTTTGATTATTG GAATGGTGCCATATTGT- ${ }^{\prime}$; antisense, $3^{\prime}$-TTTGATCGCCGG CGAAACTAATAACCTTACCACGGTATAACAGATC-5 ${ }^{\prime}$ ), and with mismatch sequence within the seed (sense, $5^{\prime}$-AAACTAG CGGCCGCTTTGATTATTGGAATGGTAAATATTGT- ${ }^{\prime}$; antisense, $3^{\prime}$-TTTGATCGCCGGCGAAACTAATAACCTTACCATT TTATAACAGATC- $5^{\prime}$ ).

\section{Protein Expression Analysis}

Cells were lysed in RIPA buffer supplemented with a complete protease inhibitor cocktail (Roche). Protein expression was examined by western blot using mouse monoclonal anti-KIAA0101 ab 56773 (Abcam, Cambridge, UK), rabbit polyclonal anti-ETS2 sc351 (Santa Cruz Biotechnology, Santa Cruz, CA, USA), and monoclonal anti- $\beta$-actin clone AC-15 (Sigma Aldrich, St Louis, MO, USA) antibodies for primary detection. Horseradish peroxidaseconjugated rabbit anti-mouse and goat anti-rabbit polyclonal secondary antibodies (Dako, Denmark) were used. Western blots were developed using Luminol (Santa Cruz Biotechnology).

\section{Proliferation and Cell Cycle Assay}

Growth curves were performed by daily counting of viable premiR-183 transfected and scramble transfected cells expressing GFP protein using an LSRII FACS flow cytometer (BD Biosciences Europe, Erembodegem, Belgium). For cell cycle distributions, premiR-183 transfected and scramble transfected cells were collected and incubated $1 \mathrm{~h}$ at $4^{\circ} \mathrm{C}$ with propidium iodide $(0.05 \mathrm{mg} / \mathrm{ml})$ solution containing Non-idet-P40 (0.05\%) for proliferation and cell cycle assays. Cells were analyzed using a FACSCalibur flow cytometer (BD Biosciences Europe, Erembodegem, Belgium) and cell cycle distribution was determined using Modfit LT $2.0^{\mathrm{TM}}$ software (Veritysoftware Inc., Topsham, ME, USA). BrdU incorporation assays were performed using the APC-BrdU flow kit (BD Pharmingen), following the manufacturer's protocol.

\section{Chromatin Immunoprecipitation Assays}

HeLa cells were fixed in medium with $1 \%$ formaldehyde for $20 \mathrm{~min}$ and then harvested in SDS lysis buffer $(50 \mathrm{mM}$ Tris $\mathrm{HCl} \mathrm{pH}$ 8.1, $10 \mathrm{mM}$ EDTA, and 1\% SDS) with added protease inhibitors. Chromatin was then sonicated using 25 cycles of $30 \mathrm{~s}$ ON/OFF on a Diagenode UCD-300 sonicator. Sheared chromatin was pre-cleared using sepharose beads (Sigma Aldrich) followed by overnight incubation with $5 \mu \mathrm{g}$ anti-ETS2 (sc-351, Santa Cruz Biotechnology) or $5 \mu \mathrm{g}$ of rabbit anti-mouse IgG (Dako) as a background control. Samples were then incubated with blocked GammaBind G Sepharose Beads (GE Healthcare Life Sciences, Freiburg, Germany) and eluted in elution buffer $\left(0.1 \mathrm{M} \mathrm{NaHCO}_{3}\right.$, $1 \%$ SDS). Untreated chromatin was used as input. Purified DNA was used in $\mathrm{QPCR}$ reactions for analysis. All primers are listed in Table S4 in Supplementary Material.

\section{Results}

\section{miRNAs are Globally Deregulated in Aggressive vs. Non-Aggressive PRL Tumors}

In 12 PRL tumors classified according to the new classification (7) and split into two groups (9): aggressive tumors $(n=4)$ and non-aggressive tumors $(n=8)$ (Table 1, tumors in bold), miRNA expression levels were assessed using Human miRNA Microarray V3 (Agilent Technologies) and analyzed with GeneSpring Software 7.0. Signature comparison revealed a down-regulation of 11 miRNAs in aggressive compared to non-aggressive tumors (Table 2). A technical validation of microarrays was performed using TaqMan Low Density Assay (TLDA, Applied Biosystems) on the same samples and 9 of the 11 miRNAs interrogated by the TLDA assays presented the same changes in expression (Table 2).

\section{miR-183 Appeared as a Main miRNA Involved in Progression Toward Aggressiveness and Malignancy}

Previous transcriptomic analysis using Codelink microarrays had been performed on 12 out of the 26 PRL tumors (Table 1, tumors with ${ }^{*}$ ) and had revealed the deregulation of specific genes involved in the control of cell cycle and proliferation and interconnected in a pathway specifically up-regulated in aggressive tumors $(6,9)$. This increased proliferation specifically in aggressive tumors is consistent with the clinical data, the Ki-67 and p53 labeling and the classification recently proposed (7). For the purpose of simplification, herein, we will refer to this pathway as the "aggressive pathway" (Figure 1).

In order to identify miRNA potentially involved in tumoral progression toward aggressive and malignant phenotype, we used the following criteria: (1) miRNA targets (predicted by databases and already published targets) should be linked to the "aggressive pathway"; (2) targets mRNA expression should be inversely correlated to miRNA expression at mRNA level; (3) significant correlation should be observed between miRNA expression and 
TABLE 2 | Deregulated miRNA in aggressive vs. non-aggressive tumors

\begin{tabular}{|c|c|c|c|c|c|c|c|c|c|}
\hline \multirow[t]{2}{*}{ Name } & \multirow[t]{2}{*}{ Accession $^{a}$} & \multirow[t]{2}{*}{ Chromosome } & \multirow[t]{2}{*}{ Position } & \multirow[t]{2}{*}{ Strand } & \multirow[t]{2}{*}{ Cytoband } & \multicolumn{2}{|c|}{ Agilent microarrays } & \multicolumn{2}{|c|}{ TLDA assays } \\
\hline & & & & & & $F^{b}$ & $p$-Value ${ }^{c}$ & $F C^{b}$ & $p$-Value ${ }^{c}$ \\
\hline hsa-miR-183 & MI0000273 & 7 & $129414745-129414854$ & {$[-]$} & q32.2 & -2.74 & 0.018 & -2.23 & 0.0134 \\
\hline hsa-miR-148a & MI0000253 & 7 & 25989539-25989606 & {$[-]$} & p15.2 & -2.56 & 0.030 & -2.46 & 0.0444 \\
\hline hsa-miR-375 & MI0000783 & 2 & $219866367-219866430$ & {$[-]$} & q35 & -2.39 & 0.013 & -2.01 & 0.0233 \\
\hline hsa-miR-342-3p & Ml0000805 & 14 & $100575992-100576090$ & {$[+]$} & q32.2 & -2.07 & 0.050 & -2.74 & 0.0424 \\
\hline hsa-miR-23b & MI0000439 & 9 & $97847490-97847586$ & {$[+]$} & q22.32 & -1.95 & 0.032 & -1.83 & 0.0091 \\
\hline hsa-miR-744 & MI0005559 & 17 & $11985216-11985313$ & {$[+]$} & p12 & -1.93 & 0.015 & -2.93 & 0.0009 \\
\hline hsa-miR-98 & MI0000100 & $x$ & $53583184-53583302$ & {$[-]$} & p11.22 & -1.92 & 0.028 & -1.72 & 0.048 \\
\hline hsa-miR-340* & Ml0000802 & 5 & $179442303-179442397$ & {$[-]$} & q35.3 & -1.86 & 0.015 & \multicolumn{2}{|c|}{ No probe } \\
\hline hsa-miR-574-3p & MI0003581 & 4 & 38869653-38869748 & {$[+]$} & p14 & -1.84 & 0.047 & -2.12 & 0.0337 \\
\hline hsa-miR-331-3p & MI0000812 & 12 & $95702196-95702289$ & {$[+]$} & q22 & -1.83 & 0.012 & -1.87 & 0.0143 \\
\hline hsa-miR-1280 & MI0006437 & 3 & $128081008-128081101$ & {$[+]$} & $\mathrm{q} 21.3$ & -1.57 & 0.035 & \multicolumn{2}{|c|}{ No probe } \\
\hline
\end{tabular}

${ }^{a}$ Accession number from MirBase.

${ }^{b} \mathrm{FC}$, fold change of miRNA expression in A tumors compared to NA tumors.

${ }^{c} p$-Value from Student's test.

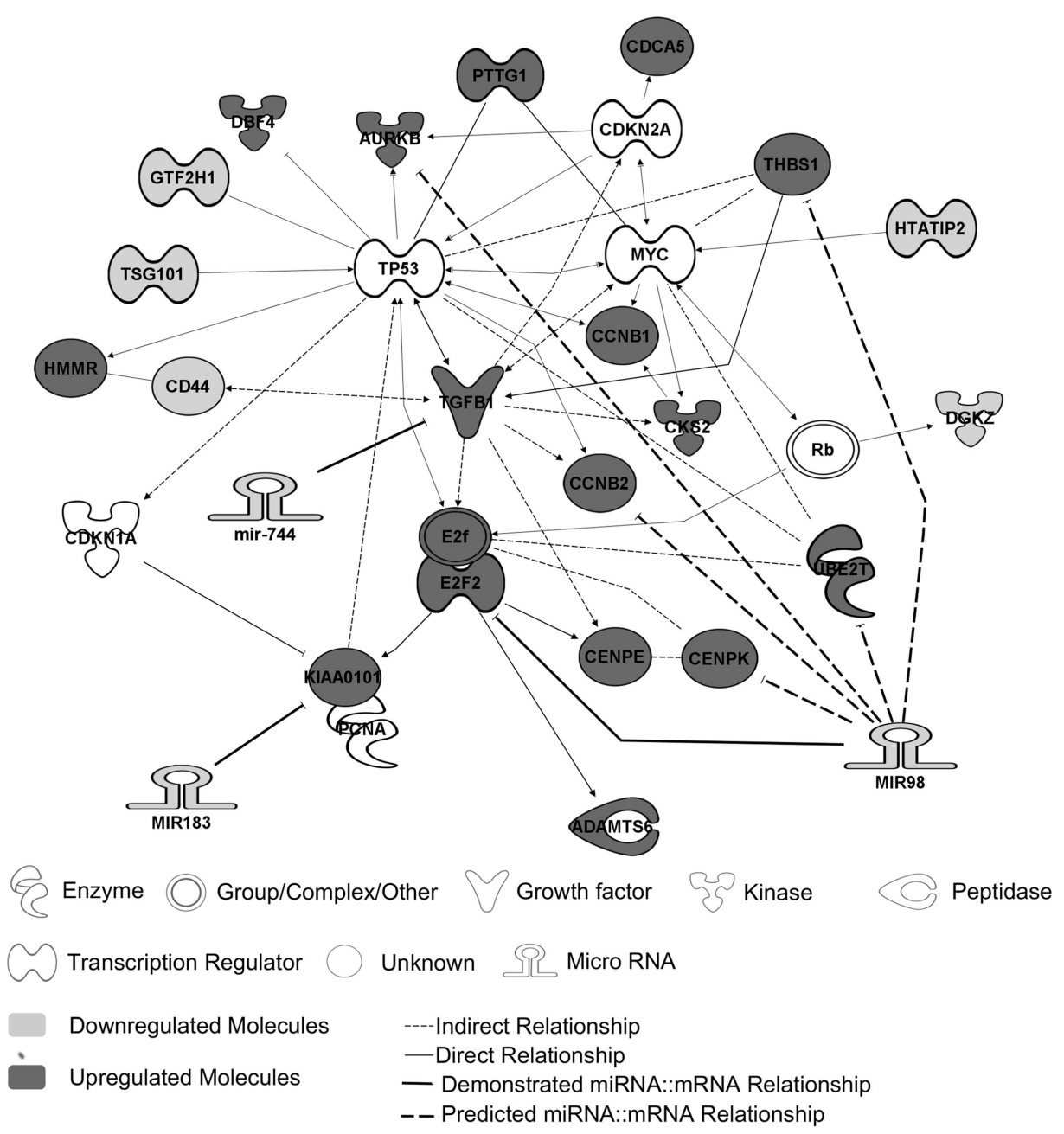

FIGURE 1 | The "aggressive pathway." Up-regulated genes (red) and downregulated genes (blue) are interconnected in a pathway involved in cell cycle control. MiRNAs and their predicted targets are linked by bold lines. The demonstrated targets are linked by solid lines, whereas predicted ones are linked by dotted lines. The genes HTATIP2, DGKZ, CD44, TSG101, and GTF2H1 are downregulated because of an allelic loss (chr11p region) (9). 
the main molecular markers of cell cycle taking into account in the tumor grading (i.e., Ki-67 and p53).

Two databases (TargetScan and microRNA.org) were used in order to identify known and predicted targets of the 11 deregulated miRNA and lead to the identification of 541 mRNA targets. Among these, only 22 genes presented a variation of expression in aggressive vs. non-aggressive tumors that was inversely correlated to their associated miRNA. Using Ingenuity Pathway Analysis Software on these 22 genes, we found that nine of these genes were linked to the "aggressive pathway" and were predicted to be regulated by four miRNAs (miR-183, miR-340*, miR98, and miR-744) (Table 3). Finally, we assessed the correlation between the four miRNA expression and Ki-67 and p53 labeling in the 26 PRL tumors and it appeared that only miR-183 showed a significant inverse correlation with both cell cycle markers (miR-183:Ki-67 $r=-0.58, p=0.002$; miR-183:p53 $r=-0.59$; $p=0.0014$ ) (Table 3). Thus, we focused our attention on miR-183 that is down-regulated in aggressive vs. nonaggressive tumors and its predicted target KIAA0101 that is significantly up-regulated in aggressive vs. non-aggressive PRL tumors (Figure 2). Finally, KIAA0101 expression was also significantly correlated with Ki-67 $(r=0.58 ; p=0.0018)$ and p53 $(r=0.53$; $p=0.0054)$.

\section{miR-183 Regulates KIAA0101 by Direct Interaction with $3^{\prime}$-UTR}

In order to verify miR-183 truly regulate its predicted target, we over-expressed this miRNAs using pre-miR miRNA precursors in HeLa and ZR-75-1 cell lines and measured the effect on the expression levels of the predicted target by RT-qPCR. These cell lines were used because the miRNAs of interest are expressed at very low levels endogenously and present two different proliferation rates (very high with HeLa cells and low with ZR-75-1). Post-transcriptional regulation of KIAA0101 expression by miR-183 was assessed in vitro by monitoring KIAA0101 mRNA and protein levels in HeLa and ZR-75-1 cell lines $48 \mathrm{~h}$ after transfection of pre-miRNA-183. First, we confirmed that transfection of pre-miRNA-183 leads to a strong and significant overexpression of mature miR-183 using TaqMan microRNA Assay (Figure 3A). Following miR-183 overexpression, we observed a strong decrease in KIAA0101 mRNA and protein levels in both cell lines (Figure 3A). The miR-183 was found to inhibit KIAA0101 expression by directly interacting with mRNA $3^{\prime}$-UTR as shown by luciferase-reporter assay. Moreover, the specificity of miR-183 binding was assessed using a mutation in the sequence of KIAA0101 that is bound by miR-183 seed (Figure 3B).

\section{miR-183 Overexpression Decreases Cell Proliferation}

The criteria used to identify candidate miRNAs involved in aggressiveness were strongly linked to proliferation as it is the main difference between non-aggressive and aggressive PRL tumors. Thus, we assessed the effect of miR-183 overexpression on HeLa and ZR-75-1 cell lines. We performed growth curves on three independent experiments overexpressing miR-183 in each cell line. As shown in Figure 4A, miR-183 overexpression in HeLa and ZR-75-1 cell lines led to a significant slowdown in cell growth. Moreover, evaluation of the distribution of cell cycle phases at $120 \mathrm{~h}$ after miR-183 overexpression, using FACS analysis with propidium iodide labeling, showed that $S$ phase tended to be delayed, which could explain the decrease of proliferation rate (Figure 4B), this was confirmed by a BrdU incorporation assay (data not shown). These results strongly suggest the involvement of miR183 loss in control of proliferation and thus in the progression toward aggressive phenotype.

\section{miR-183 Expression is Controlled by the Transcription Factor ETS2}

The main mechanisms revealed to date underlying the deregulation of miRNA expression in cancers are changes in chromosome copy number or DNA methylation (32). The analysis of

TABLE 3 | Predicted target of deregulated miRNA with inverse correlation in expression level.

\begin{tabular}{|c|c|c|c|c|c|c|c|c|c|c|}
\hline $\begin{array}{l}\text { miRNA } \\
\text { name }\end{array}$ & Accession $^{a}$ & $F C^{b}$ & $p$-Value ${ }^{c}$ & $\begin{array}{l}\text { Gene } \\
\text { name }\end{array}$ & RefSeq & $F^{d}$ & $p$-Value ${ }^{c}$ & $\begin{array}{c}\text { Correlation }^{\mathrm{e}} \\
\text { miRNA:mRNA } \\
(r ; p)\end{array}$ & $\begin{array}{c}\text { Correlation }^{f} \\
\text { miRNA:Ki-67\% } \\
(r ; p)\end{array}$ & $\begin{array}{c}\text { Correlation }^{f} \\
\text { miRNA:P53\% } \\
(r ; p)\end{array}$ \\
\hline miR-183 & Ml0000273 & -2.74 & 0.018 & KIAA0101 & NM_014736.4 & 3.071 & 0.0002 & $-0.87 ; 0.0001$ & $-0.58 ; 0.002$ & $-0.59 ; 0.0014$ \\
\hline $\operatorname{miR}-340^{*}$ & MI0000802 & -1.86 & 0.015 & NEK2 & NM_002497.2 & 16.340 & 0.0077 & $-0.53 ; 0.0475$ & $-0.24 ; \mathrm{ns}$ & $-0.19 ; \mathrm{ns}$ \\
\hline \multirow[t]{5}{*}{ miR-98 } & MI0000100 & -1.92 & 0.028 & AURKB & NM_004217.2 & 5.022 & 0.0002 & $-0.75 ; 0.0042$ & $-0.38 ; 0.0263$ & $-0.19 ; \mathrm{ns}$ \\
\hline & & & & CCNB2 & NM_004701.2 & 2.278 & 0.0084 & $-0.76 ; 0.0032$ & & \\
\hline & & & & CENPK & NM_022145.3 & 2.468 & 0.0009 & $-0.89 ; 0.0001$ & & \\
\hline & & & & UBE2T & NM_014176.3 & 3.810 & 0.0236 & $-0.53 ; 0.0478$ & & \\
\hline & & & & E2F2 & NM_177733.6 & 3.043 & 0.0076 & $-0.56 ; 0.0340$ & & \\
\hline miR-744 & Ml0005559 & -1.93 & 0.015 & TGFB1 & NM_000660.4 & 2.640 & 0.0079 & $-0.55 ; 0.0408$ & $-0.31 ; \mathrm{ns}$ & $-0.31 ; \mathrm{ns}$ \\
\hline
\end{tabular}

In miRNA name * stands for "minor miRNA" meaning the miRNA originating for the preferentially degraded strand.

${ }^{a}$ Accession number from Mirbase.

${ }^{b} \mathrm{FC}$, fold change of miRNA expression in A tumors compared to NA tumors (26 tumors).

${ }^{c} p$-Value from Student's test comparing A vs. NA tumors.

${ }^{d}$ Fold change of gene expression in A vs. NA tumors (26 tumors).

${ }^{e}$ Correlation coefficient calculated between miRNA expression and their target gene (miRNA:mRNA) using Pearson test. Coefficient (r) and $p$-value ( $p$ ) are given in that for each couple. ${ }^{f}$ Correlation coefficient calculated between miRNA expression and Ki-67\% (miRNA:Ki67\%) or P53\% (miRNA:P53\%) using Spearman test. Coefficient (r) and p-value (p) are given in that for each couple. 


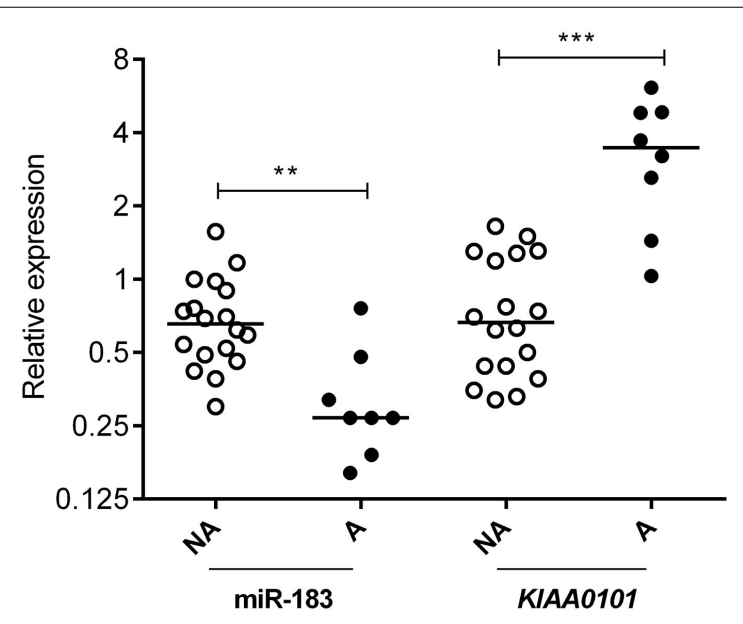

FIGURE 2 | Expression of miR-183 and its predicted target KIAA0101 in human PRL tumors. Relative expression of miR-183 and KIAA0101 target gene was assessed by RT-qPCR in aggressive $(\mathrm{A} ; n=8)$ and non-aggressive (NA; $n=18$ ) human PRL tumors. Statistical relevance was tested using unpaired $t$-test. ${ }^{\star} p<0.05 ;{ }^{* *} p<0.005 ;{ }^{* \star *} p<0.0001$.

these mechanisms in PRL tumors showed no significant differences between aggressive and non-aggressive tumors for miR183 miRNA analyzed (data not shown). We therefore decided to search for a transcription factor that could potentially be involved in regulating the expression of this miRNA. Computational analysis of miR-183 regulatory region using PROMO algorithm (33, 34) showed that 60 transcription factors could potentially regulate miR-183 (Table S4 in Supplementary Material). Correlations between the expression of transcription factors and miRNA were calculated using Spearman test and only ETS2:miR183 $(r=0.43$, $p=0.0167$ ) showed significant correlation in the pituitary tumors studied, moreover, ETS2 showed a significant down-regulation at the mRNA level in the aggressive tumors compared to the nonaggressive ones (Figure 5A; Table S4 in Supplementary Material). We then tested the effect of overexpressing ETS2 in HeLa and ZR-75-1 cell lines on miR-183 and its target KIAA0101. As shown in Figure 5B, overexpression of ETS2 in both cell lines significantly increased miR-183 expression. Moreover, exogenous expression of ETS2 led to a decrease of KIAA0101 at the protein level potentially through the observed increase in expression of miR-183. Finally, chromatin immunoprecipitation experiments revealed that ETS2 directly regulates miR-183 expression by binding its regulatory regions (Figure 5C). All these results seemed to show that ETS2 is involved in the regulation of miR-183 and that its down-regulation in aggressive PRL tumors could explain, at least in part, the decrease of miR-183 expression.

\section{Discussion}

This study explores the role of miRNA in the progression of 26 PRL tumors with different behaviors, including 3 carcinomas and attempts to characterize the hierarchical molecular events leading to malignancy by integrating miRNA signatures with previously obtained transcriptomic and genotyping data from the same tumor samples. To reduce the complexity of the analysis, we chose to focus on genes connected to a signaling pathway that we have previously highlighted as up regulated in aggressive PRL tumors $(8,9)$. While various studies on miRNAs have compared miRNA deregulation between normal and tumoral pituitary tissues (Data S1 in Supplementary Material) thus highlighting miRNA involvement in pituitary tumorigenesis, to our knowledge, only one other study has investigated miRNA in tumoral progression by comparing the differences between adenomas and carcinomas in ACTH pituitary tumors (21). To assess the role of miRNA deregulation in the progression of PRL tumors, we performed the first global miRNA expression analysis in aggressive and non-aggressive PRL tumors. Eleven miRNAs were identified as significantly deregulated between the two tumor groups. Some of these deregulated miRNA have been described in studies on pituitary tumorigenesis (tumoral vs. normal pituitary tissues) (Table S1 in Supplementary Material). For example, miR-98 and miR-23b are involved in tumorigenesis of pituitary tumors and are down-regulated in GH tumors compared to normal pituitary samples and can directly inhibit HMGA2 expression (35). Up-regulation of the HMGA2 gene has a critical role in pituitary tumorigenesis $(24,25,29,36-38)$. Interestingly, while no change in HMGA2 expression has been observed between aggressive and non-aggressive PRL tumors, comparison with normal pituitary showed a significant increase in HMGA2 mRNA levels, consistent with a decrease in miR-23b and miR-98 expression (data not shown). Similarly, miR-744 was down-regulated in macro GH-adenomas vs. micro GH-adenomas, suggesting an anti-tumoral role for this miRNA in GH pituitary tumors (20). Among the predicted targets of the deregulated miRNAs, E2F2 and TGF $\beta 1$ have already been shown to be regulated by miR98 and miR-744, respectively $(39,40)$. E2F2 is involved in the control of the G1/S phase transition and $S$ phase progression and its overexpression has been described in many cancers, in which it is thought to promote cell proliferation (41). Moreover, the E2F family, and especially E2F1, is overexpressed in $\mathrm{GH}$ adenomas (24). Interestingly, E2F2 overexpression, in contrast to $\mathrm{E} 2 \mathrm{~F} 1$, does not activate replicative senescence pathways (42, 43). The TGF $\beta 1$ pathway was described to be decreased during pituitary tumorigenesis, especially in non-functioning adenoma, suggesting a tumor suppressor role for this gene (22). Nevertheless, a role is emerging for TGF-beta in driving tumoral progression through different mechanisms that favor immunosuppressive activity, pro-angiogenic effects, and epithelial-to-mesenchymal transition, the latter of which is important in the development of metastasis (44). Consequently, it would be interesting to explore the role of TGFB1 in PRL pituitary tumor aggressiveness and malignancy.

In order to identify candidate miRNAs involved in progression to aggressiveness and malignancy, we used criteria based on the main differences between aggressive and non-aggressive PRL pituitary tumors, which are linked to proliferation. Indeed, pathological classification showed that invasion and cell cycle markers (Ki-67, p53, and mitosis) are able to discriminate tumor grade and to predict tumor behavior (7). Moreover, we have previously described genes over-expressed in aggressive as compared to non-aggressive tumors that have a diagnostic and/or prognostic ability $(5,6)$. Using these criteria, we highlight that 
A

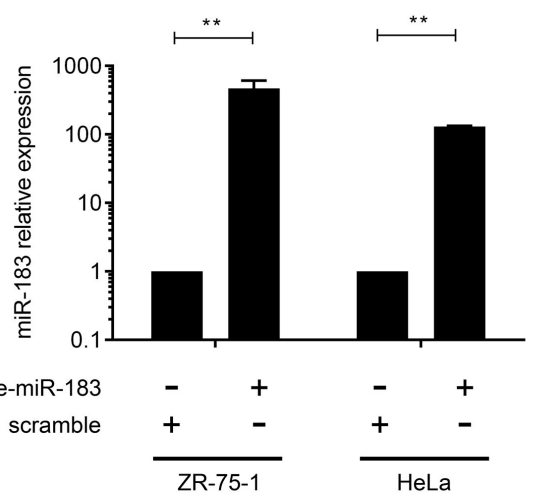

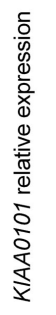
scramble
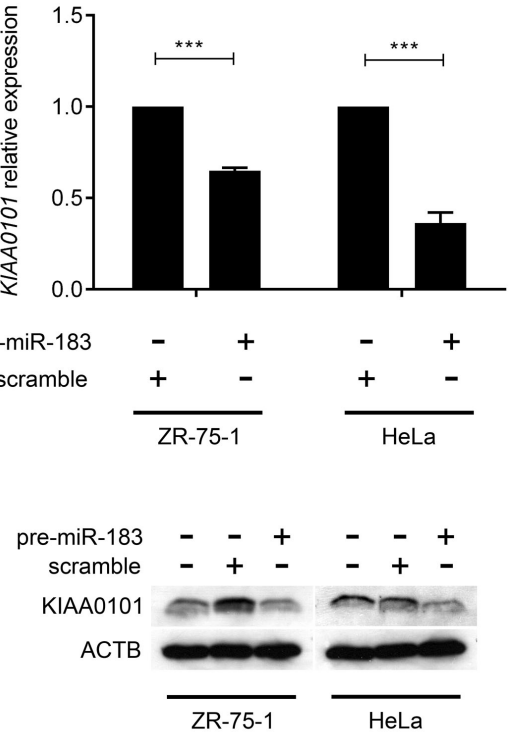

B

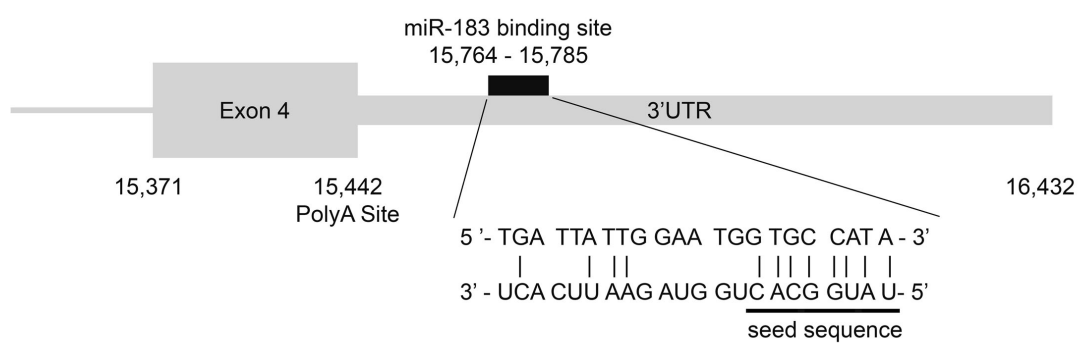

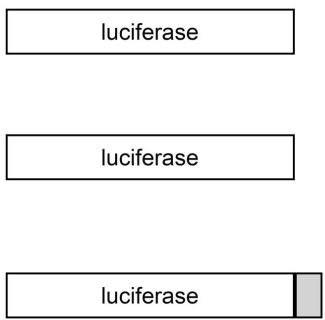

Target Sequence

Mutated Target Sequence
FIGURE 3 | miR-183 directly regulates KIAA0101 expression by binding to the $\mathbf{3}^{\prime}$-UTR. (A) miR-183 and KIAA0101 expression levels were assessed by RT-QPCR. Transfection of pre-miR-183 precursor led to a strong increase in miR-183 expression in HeLa and ZR-75-1 cell lines compared to negative control miRNA precursor transfection. Consequently, KIAA0101 expression was strongly decreased in both cell lines transfected with pre-miR-183 precursor compared to negative control. KIAA0101 protein level decreased in both cell lines overexpressing miR-183 compared to negative control (scramble) transfected cells. (B) Predicted binding site of miR-183 in KIAA0101 3' UTR was cloned $3^{\prime}$ of the luciferase sequence (match sequence). As a negative control, a mismatch sequence is the seed was cloned $3^{\prime}$ of the luciferase gene. Moreover normal luciferase was also used. The luciferase assay clearly showed that luciferase activity is decreased only when miR-183 is overexpressed in the presence of match sequence. Statistical relevance was assessed using $t$-test ${ }^{*} p<0.05$; ${ }^{* *} p<0.005 ;{ }^{* \star *} p<0.0001$.
miR-183 is significantly down-regulated in aggressive vs. nonaggressive tumors. Interestingly, miR-183 has been found to be down-regulated in neuroblastoma (45), pancreatic cancer (46), lung cancer (47,48), ovarian cancer (49), and osteosarcoma $(50,51)$ when compared to corresponding normal tissues. It has been shown in several studies that overexpression of miR-183 in 
HeLa cell line

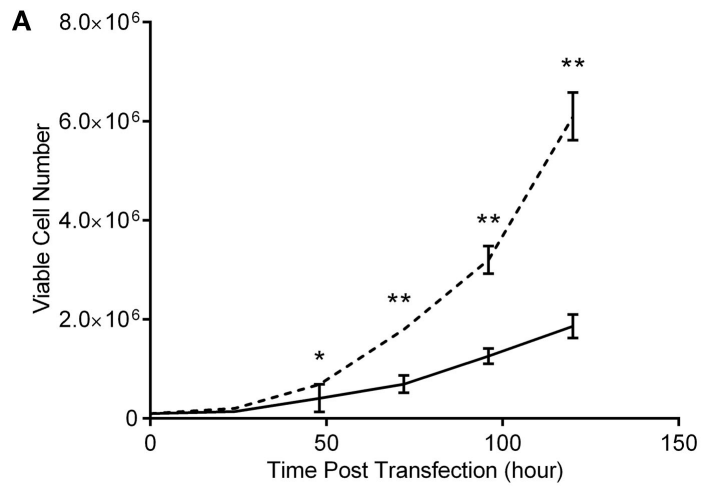

ZR-75-1 cell line

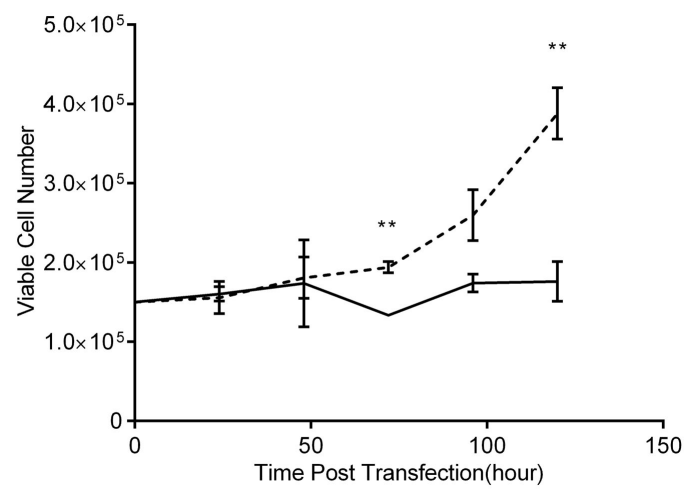

-.. Scramble Transfected

- Pre-miR-183 Transfected

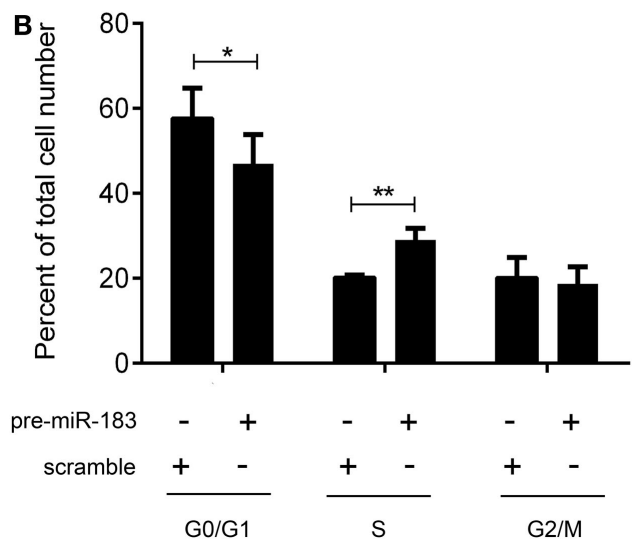

FIGURE 4 | miR-183 overexpression induces cell accumulation in S phase thus decreasing cell proliferation. (A) HeLa and ZR-75-1 cell lines overexpressing miR-183 showed a significant decrease in cell proliferation compared to scramble control transfected cells. Growth curves were performed by counting viable cells after miR-183 or scramble control transfection every day for 5 days. (B) HeLa and ZR-75-1 cell lines overexpressing miR-183 seemed to

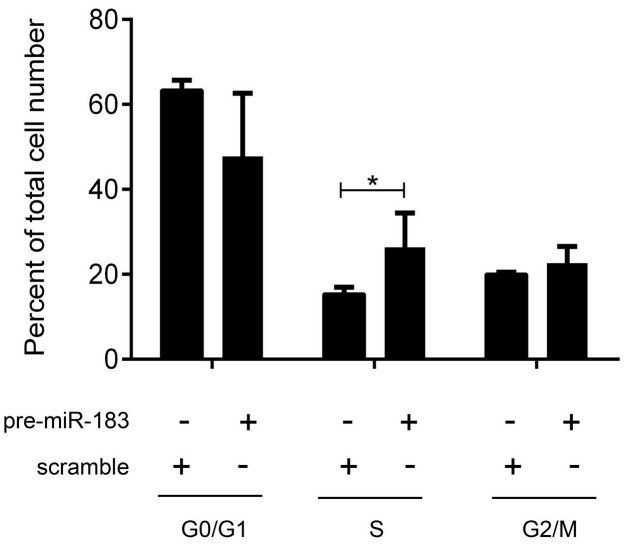

get trapped in S-phase of the cycle when compared to scramble control transfected cells. Cell cycle analysis was performed by propidium iodide staining of cells $120 \mathrm{~h}$ after miR-183 or scramble control transfection. Stained cells were analyzed on the LSRII FACS System to assess cell cycle phases. Experiments were performed in triplicate. Statistical relevance was assessed using $t$-test ${ }^{\star} p<0.05 ;{ }^{* *} p<0.005 ;{ }^{* * *} p<0.0001$. corresponding cell lines inhibits cell growth $(47,49,51)$. These data are consistent with our study corroborating the decrease in cell proliferation of HeLa and ZR-75-1 cells after transfection with miR-183. As the oncogenic or tumor suppressor role of miRNA depends on the messenger RNA they target, we applied an integrative approach combining data on miRNA global expression with those obtained previously by target prediction algorithms and transcriptomic analysis on the same human PRL tumors. Our integrative analysis has identified KIAA0101 as a new putative target for miR-183. In vitro, we show that miR183 decreases the expression of KIAA0101 at both the mRNA and protein levels by directly binding to the $3^{\prime}$-UTR. KIAA0101 is overexpressed in aggressive vs. non-aggressive PRL tumors, and moreover, KIAA0101 expression is significantly correlated with Ki-67 and p53 labeling. This is consistent with previous studies showing that KIAA0101 overexpression is often correlated with tumoral grade and lower survival in hepatocellular carcinoma (52), human non-small cell lung cancer (53), adrenocortical tumors (54), gastric cancer (55), and breast cancer (56).
Inhibition of KIAA0101 by shRNA leads to a strong inhibition of cell proliferation and particularly inhibition of S-phase progression (57). Consistent with these findings, we demonstrate that miR-183-mediated KIAA0101 silencing decreases HeLa and ZR75-1 proliferation by deregulating cell cycle progression. Finally, it is interesting to note that KIAA0101 is involved in the inhibition of p53-p21 cell cycle arrest/replicative senescence activating pathways $(55,58,59)$. Thus, the increase in KIAA0101 expression in aggressive and malignant tumors is consistent with the model of pituitary tumor progression proposed by Melmed, which posits that an inhibition of replicative senescence is necessary for tumor progression (60).

To explain the decrease in miR-183 expression in aggressive PRL tumors, we first analyzed genetic alterations and DNA methylation in regulatory region but could not detect any differences between aggressive and non-aggressive tumors at this locus (data not shown). We then analyzed the deregulation of transcriptional activators of miR-183. Among all of the transcription factors with potential involvement in the regulation of miR-183, only 

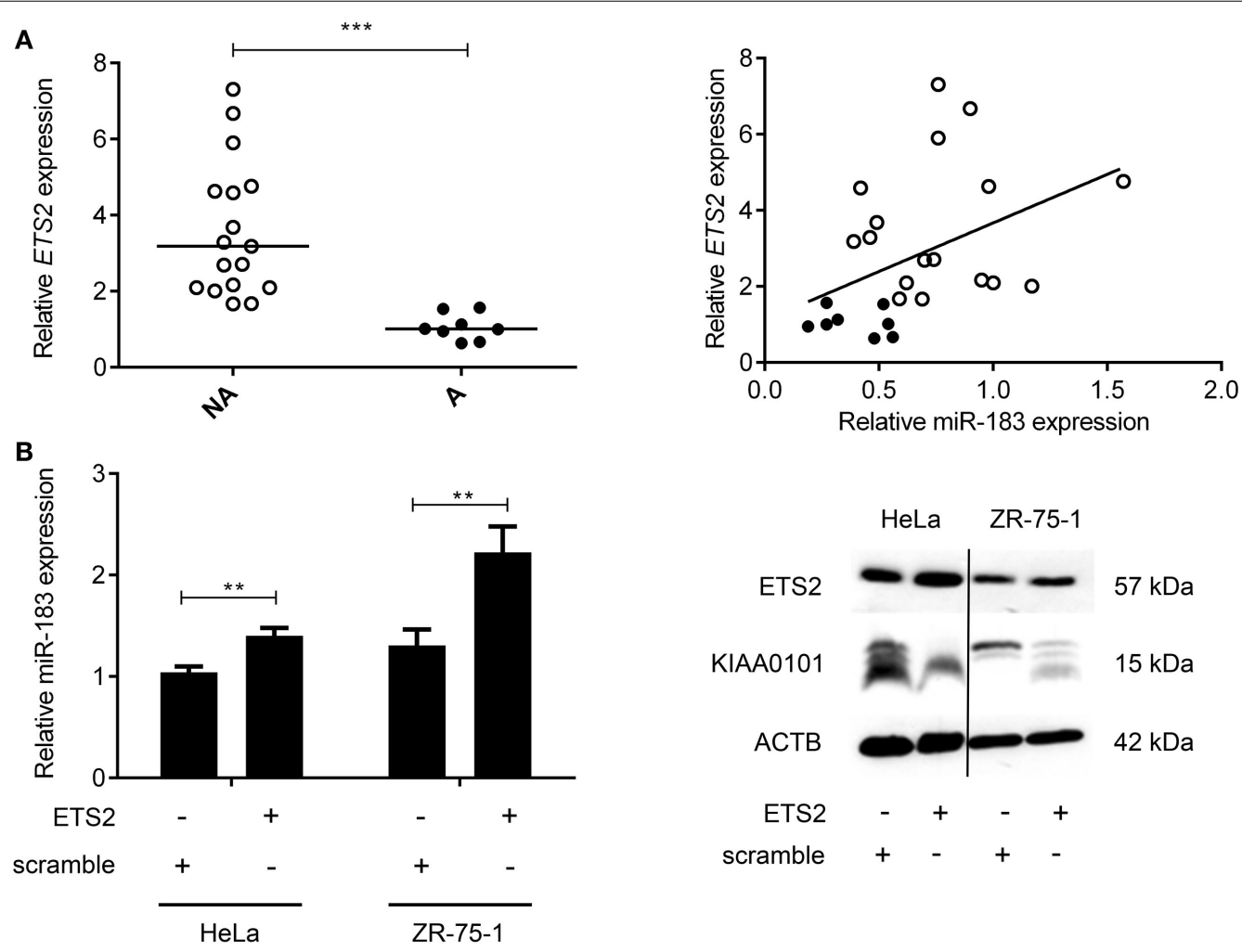

C
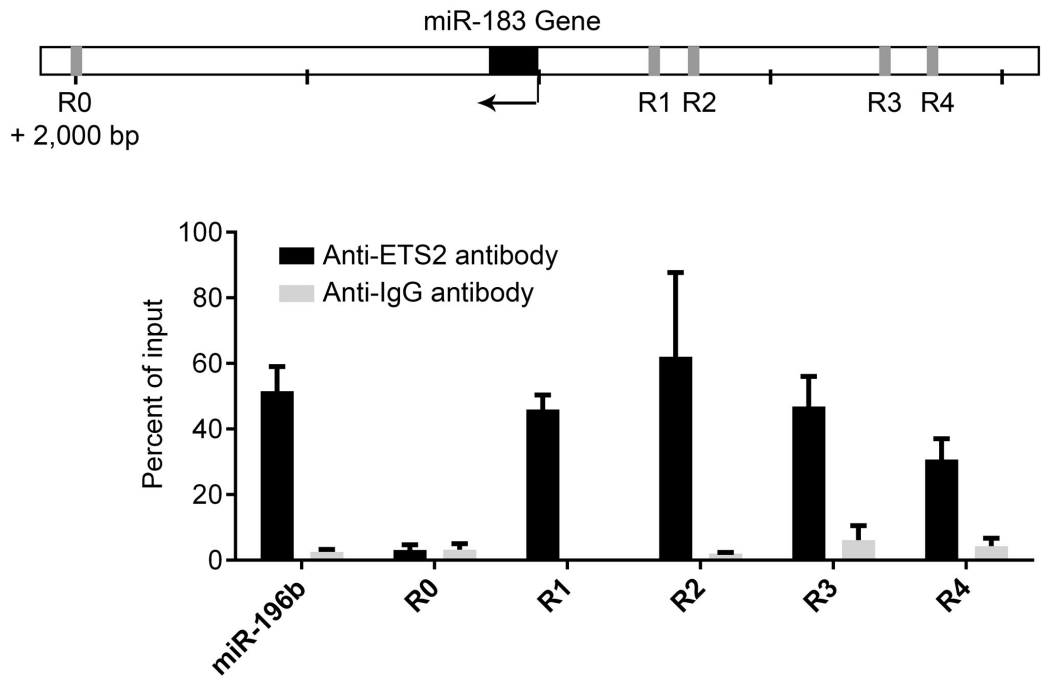

FIGURE 5 | The transcription factor ETS2 regulates miR-183 expression (A) ETS2 relative expression was assessed in 20 non-aggressive and 6 aggressive human PRL tumors by RT-qPCR and a correlation graph was made between miR-183 and ETS2 expression levels. (B) HeLa and ZR-75-1 cell lines overexpressing ETS2 showed an increased miR-183 expression compared to scramble control transfected cells. Moreover, in ZR-75-1 cells expressing ETS2,
KIAA0101 was decreased at the protein level as compared to scramble control transfected cell. (C) ChIP assays using antibody directed against ETS2 showed a significant enrichment of ETS2 binding sites in the miR-183 regulatory regions (R1-R4) by qPCR compared to background control. Regions containing no ETS2 binding sites (RO) showed no enrichment. Statistical relevance was assessed using $t$-test ${ }^{\star} p<0.05 ;{ }^{* \star} p<0.005 ;{ }^{\star \star *} p<0.0001$.
ETS2 expression correlates with miR-183 expression. Indeed, we demonstrate in this study that ETS2 activates miR-183 expression by directly binding its regulatory regions. The role of ETS 2 in tumoral progression is controversial. Nevertheless, it has been shown that KO-ETS2 in intestinal stem cells increases colonic tumor frequency (61). Moreover, ETS2 overexpression activates p53-dependent apoptosis in the context of Down's syndrome (62). Finally, in the context of pituitary adenoma, ETS2 is involved in inhibition of PRL gene expression (63), and therefore, the decrease of ETS2 mRNA in PRL tumors is consistent with the observed hyperprolactinemia. In agreement with these data, we found ETS2 to be down-regulated in aggressive vs. non-aggressive human 


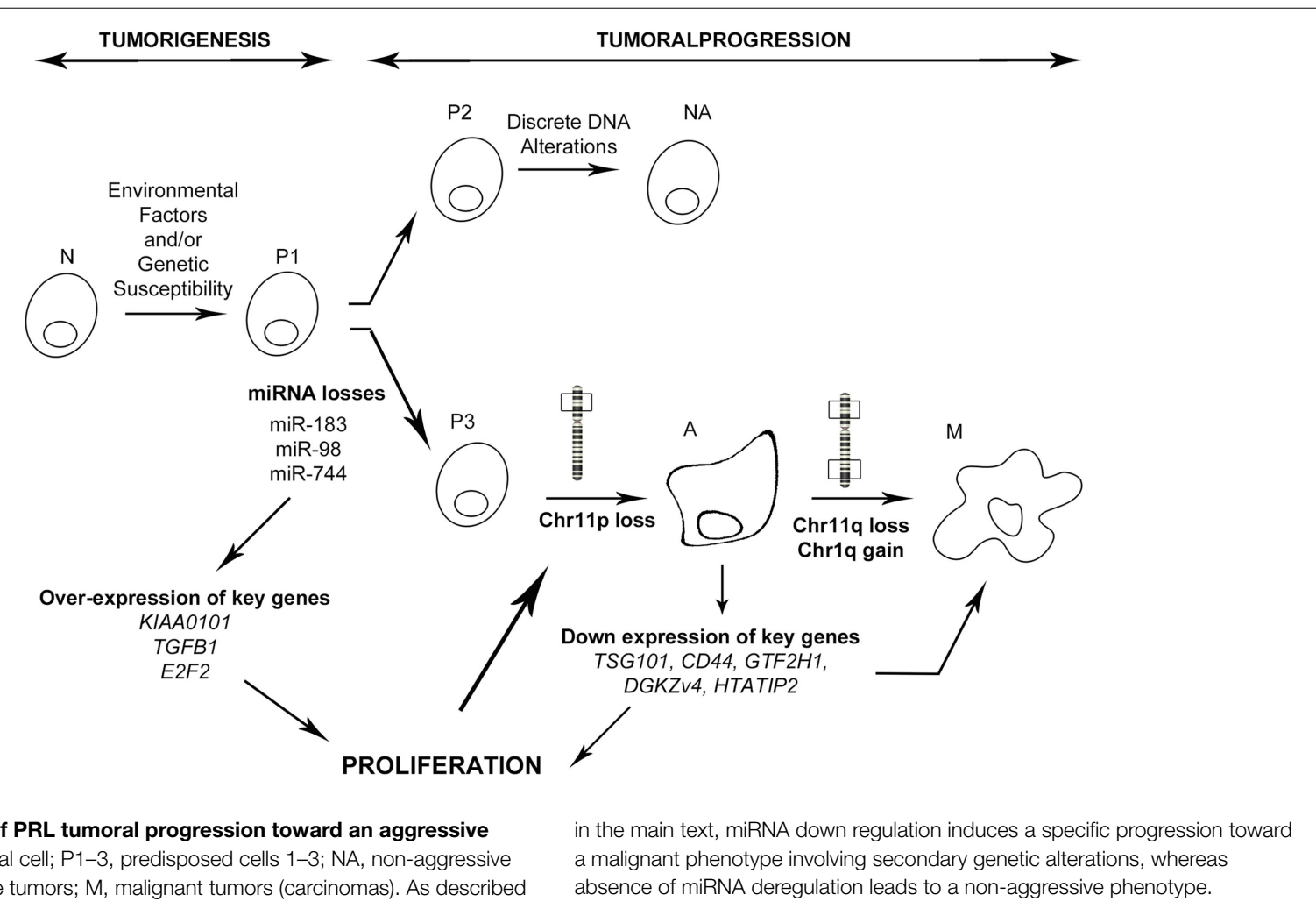

PRL tumors. Together, these data suggest a role for ETS2 downregulation in the decreased miR-183 expression observed in the same tumors.

In conclusion, integration of the miRNA signature with transcriptomic profiling and clinical-pathological features has allowed us to identify one miRNA and its new target which are strongly involved in PRL tumor progression toward aggressiveness and malignancy. In combination with our previous studies, we propose that the down-regulation of specific miRNAs such as miR-183, perhaps through the inhibition of transcription activators, leads to the overexpression of some key genes connected in the "aggressive pathway" that is specifically up regulated in aggressive tumors. This deregulation of the cell cycle would induce an uncontrolled proliferation that allows the acquisition of advantageous alterations, such as the loss of chromosome 11p, observed specifically in aggressive and malignant PRL tumors (9). This chromosomal alteration would in turn impact the expression of key genes leading to the over-activation of cell proliferation and acquisition of supplementary alterations specific to the malignant phenotype (Figure 6). Finally, we demonstrated that integrative genomic strategy applied in the same human tumors can identify candidate genes and the associated molecular mechanisms responsible for tumor progression, even from a small cohort of patients.

\section{Author Contributions}

JT and GR were responsible of the clinical aspects of the study (sample collection, pathological classification, etc.). JL, MR, JT,
GR, CL-L, AW, and AF designed the study, wrote, and revised the manuscript. Final version of the manuscript was approved by all the authors. MR, SC, CR, and APM were involved in data acquisition. APM and MR were involved in analysis and interpretation of data. CL-L, APM, and AF contributed to essential reagents or tools. Finally, all authors agree for all aspects of the work.

\section{Acknowledgments}

This work was supported by Institut National de la Santé et de la Recherche Médicale (INSERM). This work was supported by the Ligue Contre le Cancer (comités Puy de Dôme and Rhône-Alpes), Grant to Pr. JL. This work was supported by the Région RhôneAlpes (France). This work was supported by the Programme Hospitalier de Recherche Clinique National (Hypopronos no. 2743). Dr. MR received a Ph.D. fellowship from the Ministère de l'Enseignement Supérieur et de la Recherche of France. FACS facilities were kindly provided by Pr. C. Dumontet, E. CrosPerrial, and A. Evesque from the "Anticorps Anti-cancer" Lab in Centre de Recherche en Cancérologie de Lyon. Tissues were provided by Neurobiotech Bank and we kindly thank Prof. Chanson for tumour tissue \#5.

\section{Supplementary Material}

The Supplementary Material for this article can be found online at http://journal.frontiersin.org/article/10.3389/fmed. 2015.00054 


\section{References}

1. Meij BP, Lopes MB, Ellegala DB, Alden TD, Laws ER Jr. The long-term significance of microscopic dural invasion in 354 patients with pituitary adenomas treated with transsphenoidal surgery. J Neurosurg (2002) 96:195-208. doi:10. 3171/jns.2002.96.2.0195

2. McCormack AI, Wass JA, Grossman AB. Aggressive pituitary tumours: the role of temozolomide and the assessment of MGMT status. Eur J Clin Invest (2011) 41:1133-48. doi:10.1111/j.1365-2362.2011.02520.x

3. Raverot G, Castinetti F, Jouanneau E, Morange I, Figarella-Branger D, Dufour $\mathrm{H}$, et al. Pituitary carcinomas and aggressive pituitary tumours: merits and pitfalls of temozolomide treatment. Clin Endocrinol (Oxf) (2012) 76:769-75. doi:10.1111/j.1365-2265.2012.04381.x

4. Lloyd RV, Kovacs K, Young WF Jr, Farrel WE, Asa SL, Trouillas J, et al. World Health Organisation classification of tumours. In: DeLellis RA, Lloyd RV, Heitz PU, Eng C, editors. Pituitary Tumors: Introduction in Pathology and Genetics of Tumours of Endocrine Organs. Lyon: IARC Press (2004). p. 10-3.

5. Wierinckx A, Auger C, Devauchelle P, Reynaud A, Chevallier P, Jan M, et al. A diagnostic marker set for invasion, proliferation, and aggressiveness of prolactin pituitary tumors. Endocr Relat Cancer (2007) 14:887-900. doi:10.1677/ERC07-0062

6. Raverot G, Wierinckx A, Dantony E, Auger C, Chapas G, Villeneuve L, et al. Prognostic factors in prolactin pituitary tumors: clinical, histological, and molecular data from a series of 94 patients with a long postoperative follow-up. J Clin Endocrinol Metab (2010) 95:1708-16. doi:10.1210/jc.2009-1191

7. Trouillas J, Roy P, Sturm N, Dantony E, Cortet-Rudelli C, Viennet G, et al. A new prognostic clinicopathological classification of pituitary adenomas: a multicentric case-control study of 410 patients with 8 years post-operative follow-up. Acta Neuropathol (2013) 126(1):123-35. doi:10.1007/s00401-0131084-y

8. Wierinckx A, Raverot G, Nazaret N, Jouanneau E, Auger C, Lachuer J, et al. Proliferation markers of human pituitary tumors: contribution of a genomewide transcriptome approach. Mol Cell Endocrinol (2010) 326:30-9. doi:10. 1016/j.mce.2010.02.043

9. Wierinckx A, Roche M, Raverot G, Legras-Lachuer C, Croze S, Nazaret N, et al. Integrated genomic profiling identifies loss of chromosome 11p impacting transcriptomic activity in aggressive pituitary PRL tumors. Brain Pathol (2011) 21:533-43. doi:10.1111/j.1750-3639.2011.00476.x

10. Bartel DP. MicroRNAs: genomics, biogenesis, mechanism, and function. Cell (2004) 116:281-97. doi:10.1016/S0092-8674(04)00045-5

11. Calin GA, Croce CM. MicroRNA signatures in human cancers. Nat Rev Cancer (2006) 6:857-66. doi:10.1038/nrc1997

12. Ma L, Weinberg RA. MicroRNAs in malignant progression. Cell Cycle (2008) 7:570-2. doi:10.4161/cc.7.5.5547

13. Santarpia L, Nicoloso M, Calin GA. MicroRNAs: a complex regulatory network drives the acquisition of malignant cell phenotype. Endocr Relat Cancer (2010) 17:F51-75. doi:10.1677/ERC-09-0222

14. Hanahan D, Weinberg RA. Hallmarks of cancer: the next generation. Cell (2011) 144:646-74. doi:10.1016/j.cell.2011.02.013

15. Bottoni A, Piccin D, Tagliati F, Luchin A, Zatelli MC, Degli Uberti EC. miR15a and miR-16-1 down-regulation in pituitary adenomas. J Cell Physiol (2005) 204:280-5. doi:10.1002/jcp.20282

16. Bottoni A, Zatelli MC, Ferracin M, Tagliati F, Piccin D, Vignali C, et al. Identification of differentially expressed microRNAs by microarray: a possible role for microRNA genes in pituitary adenomas. J Cell Physiol (2007) 210:370-7. doi: $10.1002 /$ jcp. 20832

17. Amaral FC, Torres N, Saggioro F, Neder L, Machado HR, Silva WA Jr, et al. MicroRNAs differentially expressed in ACTH-secreting pituitary tumors. J Clin Endocrinol Metab (2009) 94:320-3. doi:10.1210/jc.2008-1451

18. Qian ZR, Asa SL, Siomi H, Siomi MC, Yoshimoto K, Yamada S, et al. Overexpression of HMGA2 relates to reduction of the let-7 and its relationship to clinicopathological features in pituitary adenomas. Mod Pathol (2009) 22:431-41. doi:10.1038/modpathol.2008.202

19. Butz H, Liko I, Czirjak S, Igaz P, Khan MM, Zivkovic V, et al. Down-regulation of Weel kinase by a specific subset of microRNA in human sporadic pituitary adenomas. J Clin Endocrinol Metab (2010) 95:E181-91. doi:10.1210/jc.20100581
20. Mao ZG, He DS, Zhou J, Yao B, Xiao WW, Chen CH, et al. Differential expression of microRNAs in GH-secreting pituitary adenomas. Diagn Pathol (2010) 5:79. doi:10.1186/1746-1596-5-79

21. Stilling G, Sun Z, Zhang S, Jin L, Righi A, Kovacs G, et al. MicroRNA expression in ACTH-producing pituitary tumors: up-regulation of microRNA-122 and 493 in pituitary carcinomas. Endocrine (2010) 38:67-75. doi:10.1007/s12020010-9346-0

22. Butz H, Liko I, Czirjak S, Igaz P, Korbonits M, Racz K, et al. MicroRNA profile indicates downregulation of the TGFbeta pathway in sporadic nonfunctioning pituitary adenomas. Pituitary (2011) 14:112-24. doi:10.1007/ s11102-010-0268-x

23. Cheunsuchon P, Zhou Y, Zhang X, Lee H, Chen W, Nakayama Y, et al. Silencing of the imprinted DLK1-MEG3 locus in human clinically nonfunctioning pituitary adenomas. Am J Pathol (2011) 179:2120-30. doi:10.1016/j.ajpath. 2011.07.002

24. D’Angelo D, Palmieri D, Mussnich P, Roche M, Wierinckx A, Raverot G, et al. Altered microRNA expression profile in human pituitary GH adenomas: downregulation of miRNA targeting HMGA1, HMGA2, and E2F1. J Clin Endocrinol Metab (2012) 97:E1128-38. doi:10.1210/jc.2011-3482

25. Palmieri D, D’Angelo D, Valentino T, De Martino I, Ferraro A, Wierinckx A, et al. Downregulation of HMGA-targeting microRNAs has a critical role in human pituitary tumorigenesis. Oncogene (2012) 31:3857-65. doi:10.1038/onc. 2011.557

26. Trivellin G, Butz H, Delhove J, Igreja S, Chahal HS, Zivkovic V, et al. MicroRNA miR-107 is overexpressed in pituitary adenomas and inhibits the expression of aryl hydrocarbon receptor-interacting protein in vitro. Am J Physiol Endocrinol Metab (2012) 303:E708-19. doi:10.1152/ajpendo.00546.2011

27. Wang C, Su Z, Sanai N, Xue X, Lu L, Chen Y, et al. microRNA expression profile and differentially-expressed genes in prolactinomas following bromocriptine treatment. Oncol Rep (2012) 27:1312-20. doi:10.3892/or.2012.1690

28. Palumbo T, Faucz FR, Azevedo M, Xekouki P, Iliopoulos D, Stratakis CA. Functional screen analysis reveals miR-26b and miR-128 as central regulators of pituitary somatomammotrophic tumor growth through activation of the PTEN-AKT pathway. Oncogene (2013) 32:1651-9. doi:10.1038/onc.2012.190

29. Leone V, Langella C, D’Angelo D, Mussnich P, Wierinckx A, Terracciano L, et al. miR-23b and miR-130b expression is downregulated in pituitary adenomas. Mol Cell Endocrinol (2014) 390:1-7. doi:10.1016/j.mce.2014.03.002

30. Zemmoura I, Wierinckx A, Vasiljevic A, Jan M, Trouillas J, Francois P. Aggressive and malignant prolactin pituitary tumors: pathological diagnosis and patient management. Pituitary (2013) 16:515-22. doi:10.1007/s11102-012$0448-y$

31. Li M, Shin YH, Hou L, Huang X, Wei Z, Klann E, et al. The adaptor protein of the anaphase promoting complex $\mathrm{Cdh} 1$ is essential in maintaining replicative lifespan and in learning and memory. Nat Cell Biol (2008) 10:1083-9. doi:10. $1038 /$ ncb 1768

32. Di Leva G, Croce CM. Roles of small RNAs in tumor formation. Trends Mol Med (2010) 16:257-67. doi:10.1016/j.molmed.2010.04.001

33. Messeguer X, Escudero R, Farre D, Nunez O, Martinez J, Alba MM. PROMO: detection of known transcription regulatory elements using species-tailored searches. Bioinformatics (2002) 18:333-4. doi:10.1093/bioinformatics/18.2.333

34. Farre D, Roset R, Huerta M, Adsuara JE, Rosello L, Alba MM, et al. Identification of patterns in biological sequences at the ALGGEN server: PROMO and MALGEN. Nucleic Acids Res (2003) 31:3651-3. doi:10.1093/nar/gkg605

35. Hebert C, Norris K, Scheper MA, Nikitakis N, Sauk JJ. High mobility group A2 is a target for miRNA-98 in head and neck squamous cell carcinoma. Mol Cancer (2007) 6:5. doi:10.1186/1476-4598-6-5

36. Finelli P, Pierantoni GM, Giardino D, Losa M, Rodeschini O, Fedele M, et al. The high mobility group A2 gene is amplified and overexpressed in human prolactinomas. Cancer Res (2002) 62:2398-405.

37. Pierantoni GM, Finelli P, Valtorta E, Giardino D, Rodeschini O, Esposito F, et al. High-mobility group A2 gene expression is frequently induced in nonfunctioning pituitary adenomas (NFPAs), even in the absence of chromosome 12 polysomy. Endocr Relat Cancer (2005) 12:867-74. doi:10.1677/erc.1.01049

38. Fedele M, Pierantoni GM, Visone R, Fusco A. Critical role of the HMGA2 gene in pituitary adenomas. Cell Cycle (2006) 5:2045-8. doi:10.4161/cc.5.18.3211

39. Bhat-Nakshatri P, Wang G, Collins NR, Thomson MJ, Geistlinger TR, Carroll JS, et al. Estradiol-regulated microRNAs control estradiol response in breast cancer cells. Nucleic Acids Res (2009) 37:4850-61. doi:10.1093/nar/gkp500 
40. Martin J, Jenkins RH, Bennagi R, Krupa A, Phillips AO, Bowen T, et al. Posttranscriptional regulation of transforming growth factor beta-1 by microRNA744. PLoS One (2011) 6:e25044. doi:10.1371/journal.pone.0025044

41. Lavia P, Jansen-Durr P. E2F target genes and cell-cycle checkpoint control. Bioessays (1999) 21:221-30. doi:10.1002/(SICI)1521-1878(199903)21:3<221: :AID-BIES6>3.0.CO;2-J

42. Johnson DG, Schwarz JK, Cress WD, Nevins JR. Expression of transcription factor E2F1 induces quiescent cells to enter S phase. Nature (1993) 365:349-52. doi:10.1038/365349a0

43. Adams PD, Kaelin WG Jr. The cellular effects of E2F overexpression. Curr Top Microbiol Immunol (1996) 208:79-93.

44. Katsuno Y, Lamouille S, Derynck R. TGF-beta signaling and epithelialmesenchymal transition in cancer progression. Curr Opin Oncol (2013) 25:76-84. doi:10.1097/CCO.0b013e32835b6371

45. Lodrini M, Oehme I, Schroeder C, Milde T, Schier MC, Kopp-Schneider A, et al. MYCN and HDAC2 cooperate to repress miR-183 signaling in neuroblastoma. Nucleic Acids Res (2013) 41:6018-33. doi:10.1093/nar/gkt346

46. Wellner U, Schubert J, Burk UC, Schmalhofer O, Zhu F, Sonntag A, et al. The EMT-activator ZEB1 promotes tumorigenicity by repressing stemness-inhibiting microRNAs. Nat Cell Biol (2009) 11:1487-95. doi:10.1038/ ncb1998

47. Wang G, Mao W, Zheng S. MicroRNA-183 regulates Ezrin expression in lung cancer cells. FEBS Lett (2008) 582:3663-8. doi:10.1016/j.febslet.2008.09.051

48. Lin Q, Mao W, Shu Y, Lin F, Liu S, Shen H, et al. A cluster of specified microRNAs in peripheral blood as biomarkers for metastatic non-small-cell lung cancer by stem-loop RT-PCR. J Cancer Res Clin Oncol (2012) 138:85-93. doi:10.1007/s00432-011-1068-z

49. Li J, Liang S, Jin H, Xu C, Ma D, Lu X. Tiam1, negatively regulated by miR-22, miR-183 and miR-31, is involved in migration, invasion and viability of ovarian cancer cells. Oncol Rep (2012) 27:1835-42. doi:10.3892/or.2012.1744

50. Zhao H, Guo M, Zhao G, Ma Q, Ma B, Qiu X, et al. miR-183 inhibits the metastasis of osteosarcoma via downregulation of the expression of Ezrin in F5M2 cells. Int J Mol Med (2012) 30:1013-20. doi:10.3892/ijmm.2012.1111

51. Zhu J, Feng Y, Ke Z, Yang Z, Zhou J, Huang X, et al. Down-regulation of miR183 promotes migration and invasion of osteosarcoma by targeting Ezrin. Am J Pathol (2012) 180:2440-51. doi:10.1016/j.ajpath.2012.02.023

52. Yuan RH, Jeng YM, Pan HW, Hu FC, Lai PL, Lee PH, et al. Overexpression of KIAA0101 predicts high stage, early tumor recurrence, and poor prognosis of hepatocellular carcinoma. Clin Cancer Res (2007) 13:5368-76. doi:10.1158/ 1078-0432.CCR-07-1113

53. Kato T, Daigo Y, Aragaki M, Ishikawa K, Sato M, Kaji M. Overexpression of KIAA0101 predicts poor prognosis in primary lung cancer patients. Lung Cancer (2012) 75:110-8. doi:10.1016/j.lungcan.2011.05.024
54. Jain M, Zhang L, Patterson EE, Kebebew E. KIAA0101 is overexpressed, and promotes growth and invasion in adrenal cancer. PLoS One (2011) 6:e26866. doi:10.1371/journal.pone.0026866

55. Liu L, Chen X, Xie S, Zhang C, Qiu Z, Zhu F. Variant 1 of KIAA0101, overexpressed in hepatocellular carcinoma, prevents doxorubicin-induced apoptosis by inhibiting p53 activation. Hepatology (2012) 56:1760-9. doi:10.1002/hep. 25834

56. Kais Z, Barsky SH, Mathsyaraja H, Zha A, Ransburgh DJ, He G, et al. KIAA0101 interacts with BRCA1 and regulates centrosome number. Mol Cancer Res (2011) 9:1091-9. doi:10.1158/1541-7786.MCR-10-0503

57. Chang CN, Feng MJ, Chen YL, Yuan RH, Jeng YM. p15(PAF) is an Rb/E2Fregulated S-phase protein essential for DNA synthesis and cell cycle progression. PLoS One (2013) 8:e61196. doi:10.1371/journal.pone.0061196

58. Yu P, Huang B, Shen M, Lau C, Chan E, Michel J, et al. p15(PAF), a novel PCNA associated factor with increased expression in tumor tissues. Oncogene (2001) 20:484-9. doi:10.1038/sj.onc. 1204113

59. Hosokawa M, Takehara A, Matsuda K, Eguchi H, Ohigashi H, Ishikawa O, et al. Oncogenic role of KIAA0101 interacting with proliferating cell nuclear antigen in pancreatic cancer. Cancer Res (2007) 67:2568-76. doi:10.1158/0008-5472. CAN-06-4356

60. Melmed S. Pathogenesis of pituitary tumors. Nat Rev Endocrinol (2011) 7:257-66. doi:10.1038/nrendo.2011.40

61. Munera J, Cecena G, Jedlicka P, Wankell M, Oshima RG. Ets2 regulates colonic stem cells and sensitivity to tumorigenesis. Stem Cells (2011) 29:430-9. doi:10. 1002/stem.599

62. Wolvetang EJ, Wilson TJ, Sanij E, Busciglio J, Hatzistavrou T, Seth A, et al. ETS2 overexpression in transgenic models and in Down syndrome predisposes to apoptosis via the p53 pathway. Hum Mol Genet (2003) 12:247-55. doi:10.1093/ hmg/ddg015

63. Day RN, Liu J, Sundmark V, Kawecki M, Berry D, Elsholtz HP. Selective inhibition of prolactin gene transcription by the ETS-2 repressor factor. J Biol Chem (1998) 273:31909-15. doi:10.1074/jbc.273.48.31909

Conflict of Interest Statement: The authors declare that the research was conducted in the absence of any commercial or financial relationships that could be construed as a potential conflict of interest.

Copyright (c) 2015 Roche, Wierinckx, Croze, Rey, Legras-Lachuer, Morel, Fusco, Raverot, Trouillas and Lachuer. This is an open-access article distributed under the terms of the Creative Commons Attribution License (CC BY). The use, distribution or reproduction in other forums is permitted, provided the original author(s) or licensor are credited and that the original publication in this journal is cited, in accordance with accepted academic practice. No use, distribution or reproduction is permitted which does not comply with these terms. 